السياسة الإرشادية الزراعية المقترحة لتقليل الفاقد من محصول الطماطم في بعض قرى منطقة امتداد أبيس

\title{
بمحافظة الإسكندرية
}

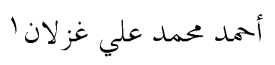

فِإن ذلك سيؤدي إلى خفض الفاقد من محصول الطماطم بنســبة \%^^,^V

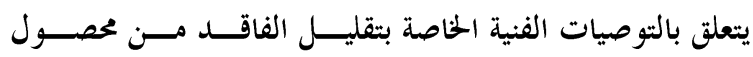

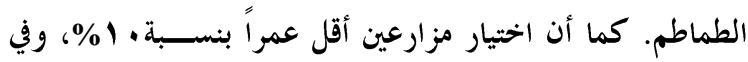

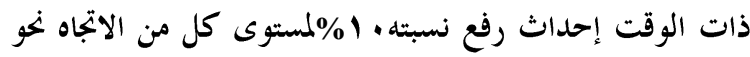

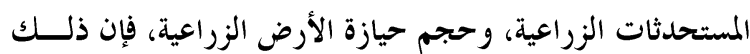

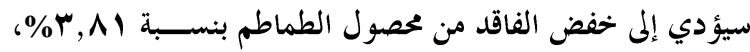
نظراً لتحسن المستوى التنفيذي للمبحوثين فيما يتعلق بالتوصيات الفنية الخاصة بتقليل الفاقد من محصول الطماطم. - - ومن دراسة أهم المثكلات التي تواجه المبحوثين عنـــد تنفيــذهم

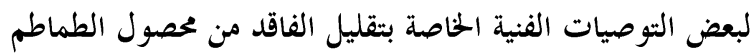

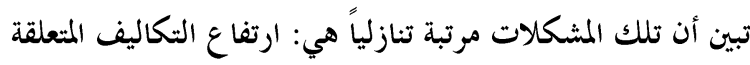

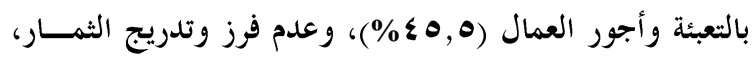
ونقص منافذ التسويق، وانتشار بعض المفاهيم الخاطئة في التسويق

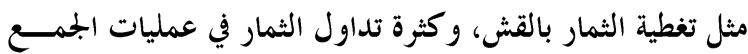
والتسويق (\%) (\%) - - وتبين أن أهم مقترحات المبحوثين للتغلب على هذه المثــكلات

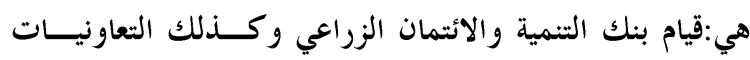

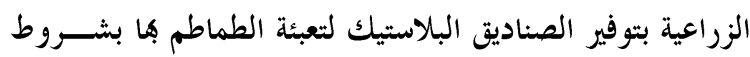

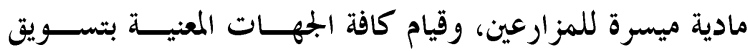

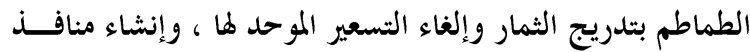

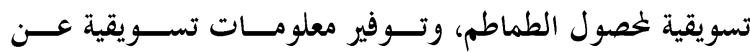

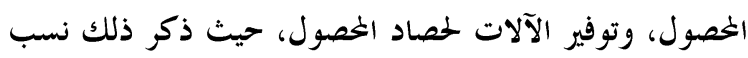

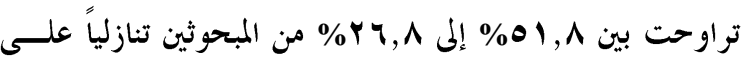
الترتيب.

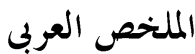

يستهدف هذا البحث معرفة العو امل التي تؤثر علــى اســتجابة

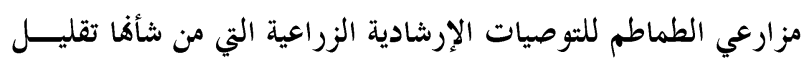

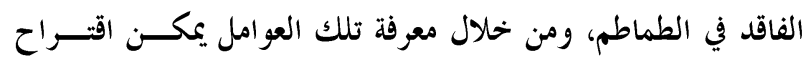

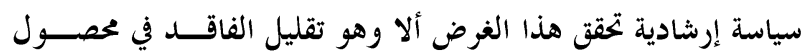
الطماطم لدى مزارعيها بمنطقة البحث. ولتحقيق ذلك كله تمت دراسة إسة

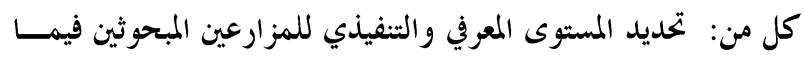

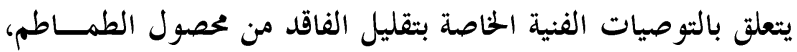

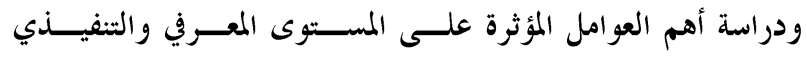

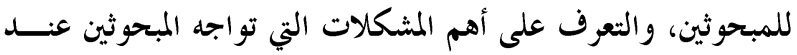

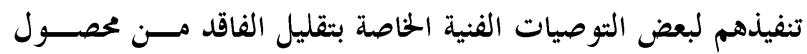
الطماطم ومقترحاتم للتغلب على هذه المثكلات. وتم بمع البيانــات

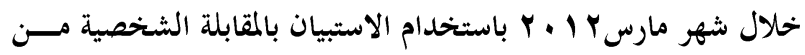

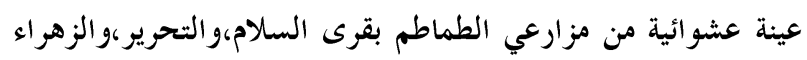

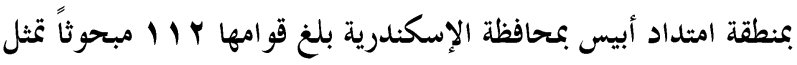

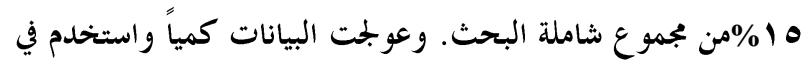
عرضها وتحليلها مصفوفة الارتباط وأسلوب الانحدار المتعدد وحساب الاختبارات الإحصائية R, R, R, Tمعامل التحديد المعدل).

$$
\text { وتمثلت أهم النتائج فيما يلي: }
$$

- - بلغت نسبة المبحوثين الذين يعرفون التوصيات الفنيـة الخاصسـة

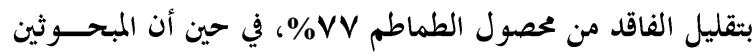

$$
\text { الذين يقومون بتنفيذها بلغت نسبتهم • }
$$

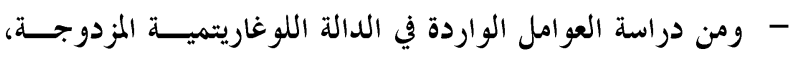

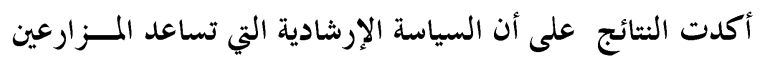

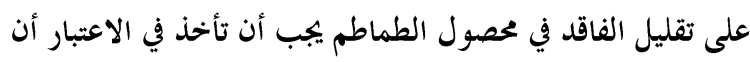

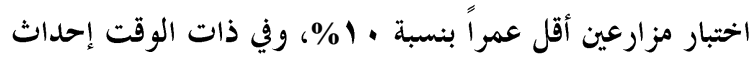
رفع نسبته • 1\% لمستوى كل من المستوى التعليمي، والإلمام العام

'باحث بععهد بحوث الإرشاد الزراعي والتنمية الريفية-مركز البحوث الزراعية

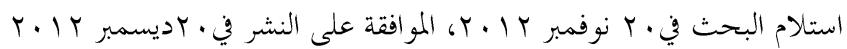


زراعية من ناحية أخرى، فإن هذا البحث يسعى لتحقيق عدد مــن

$$
\text { الأهداف أهمها: }
$$

1 - تحديد المستوى المعر في والتنفيذي للمزارعين المبحوثين فيما يتعلق بالتوصيات الفنية الخاصة بتقليل الفاقد من محصول الطماطم. r-دراسة أهم العوامل المؤثرة على المستوى المعــــفي و التنفيــــي للمزارعين المبحوثين فيما يتعلق بالتوصيات الفنية الخاصة بتقليل

$$
\text { الفاقد من مصول الطماطم. }
$$

ب - التعرف على أهم المشكلات التي تواجه المزارعين المبحوثين عند

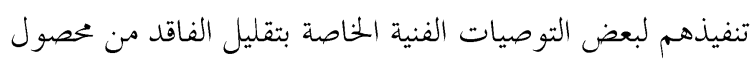

$$
\text { الطماطم ومقترحاهم للتغلب عليها. }
$$

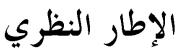

تعبر المعرفة عن حصيلة الفرد من المعلومات والأفكار التي تعطى

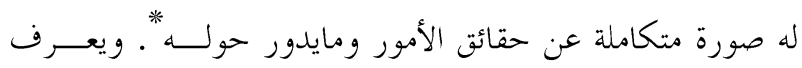

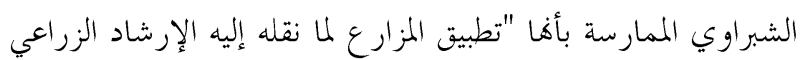

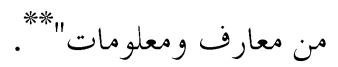

وقد أكدت نتائج دراسة كل من زقيزق

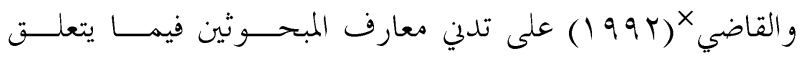

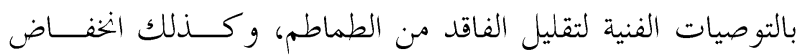
مستوى تطبيق الغالبية العظمى منهم لتلك التوصيات.

\section{الأسلوب البحثي}

منطقة البحث: أجري هذا البحث في محافظة الإسكندرية باعتبارها من المحافظات الرئيسية لزراعة مصصول الطماطم،حيث بلغت المساحة

*عبد الفتاح الديدي، سوسيولوجية المعرفة، مقال منشور بجريدة الأهرام، القاهرة،

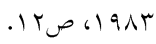
**** عبد العزيز حسن الشبراوي ، دراسة مقارنة لأثر بعض الطرق الإرشادية المستخدمة

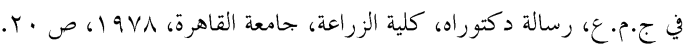

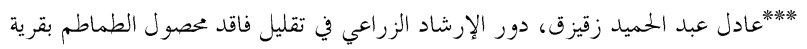
كوم البركة بمركز كفر الدوار - محافظة البحيرة، رسالة ماجستير، قسم الإرشاد

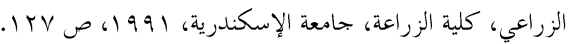

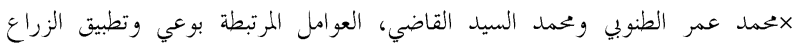

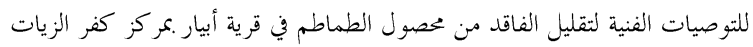

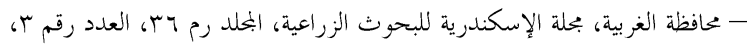

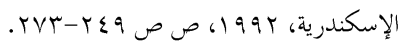

\section{المقدمة و المشكلة البحثيــة}

تحتل الطماطم المرتبة الأولى في الأهمية بالنسبة لماصيل الخضر في

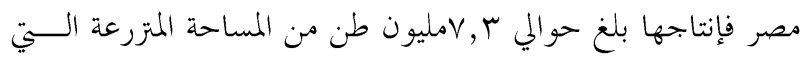

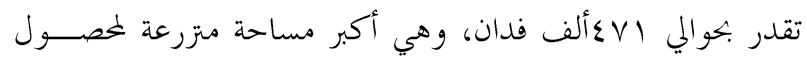

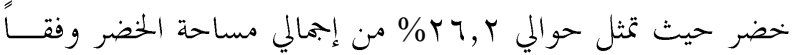

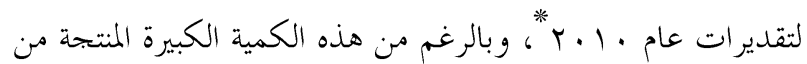

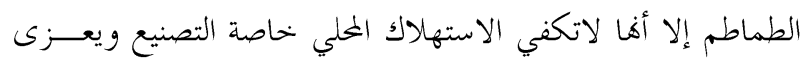

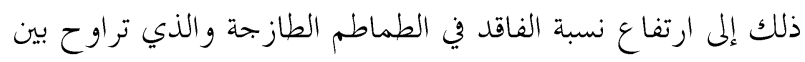

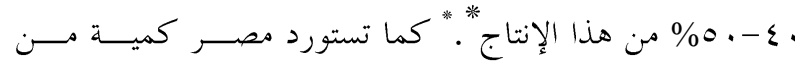

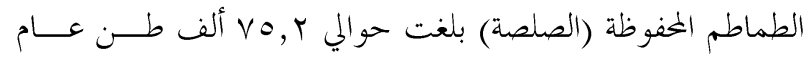

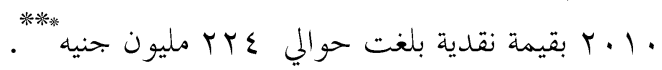
ولمواجهة زيادة نسبة الفاقد في محصول الطماطم التي تحدث منذ

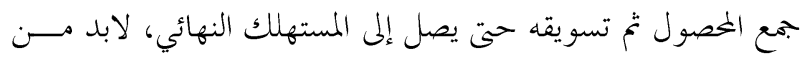

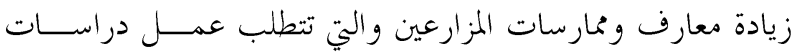

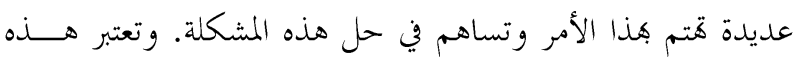
الدراسة أحد الإسهامات الضرورية للإجابة على بعض التســاؤلات

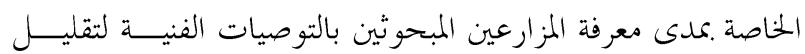

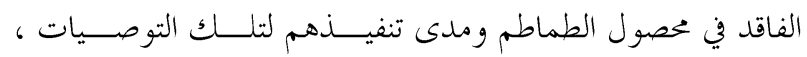

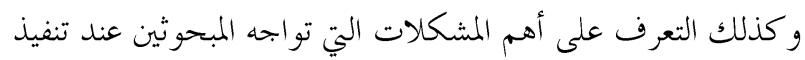

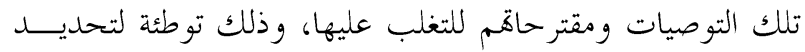
السياسة الإرشادية- الاقتصادية التي تستهدف تقليـلـل الفاقــــــي في الطماطم.

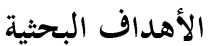

تمشياً مع أبعاد المشكلة السابق عرضها ألا وهي ارتفاع نســبة الفاقد في الطماطم والتي تعتبر مشكلة اقتصادية من ناحية وإرشادية

وزارة الزراعة واستصلاح الأراضي، قطاع الشئون الاقتصادية، الإدارة المركزية للاقتصاد

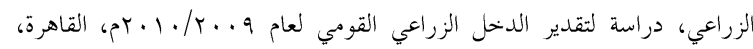

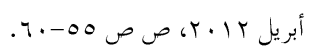
** عواد محمد حسين وأممد جمال الدين مدكور، الترشيد الاقتصادي للفاقد في ثمار

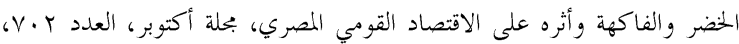

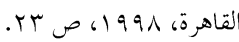

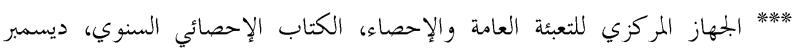

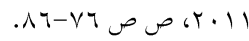


المستوى المعرفي للمبحوثين فيما يتعلق بالتوصيات الفنية الحخاصسـة

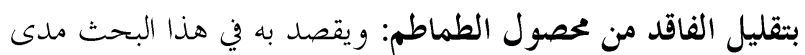

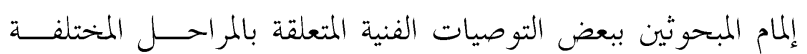

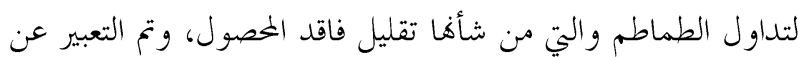

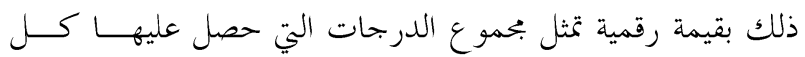

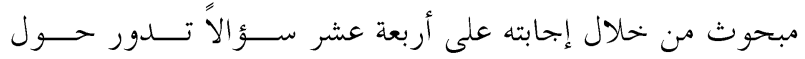

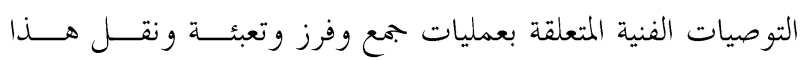

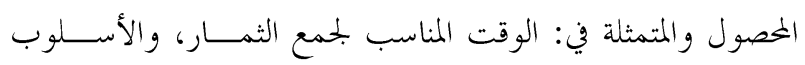

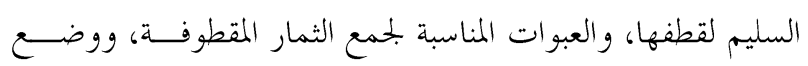

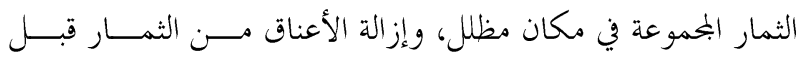
تعبئتها، والتنظيف التام للثمار من أي أتربة عالقة هيا قبل تعبئتها، واستخدام الصناديق البلاستيك في تســـويقها، وتـــــيج الثمــار، وتوحيد درجة نضجها بالعبوات، و المستوى المناسب لمليء العبوات

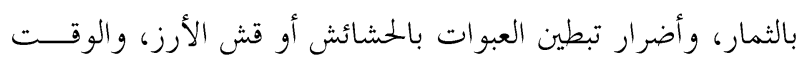

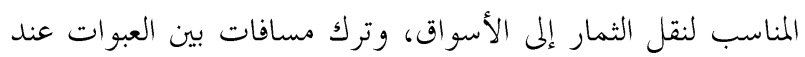

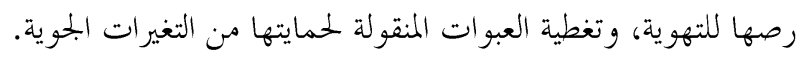
المستوى التنفيذي للمبحوثين فيما يتعلق بالتوصيات الفنية الخاصة

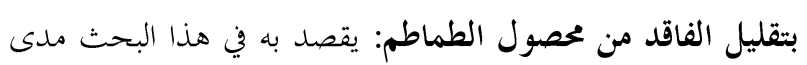

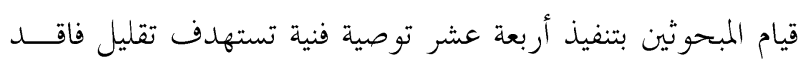

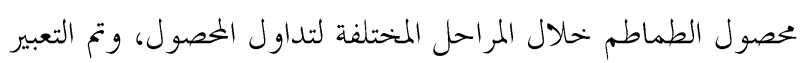

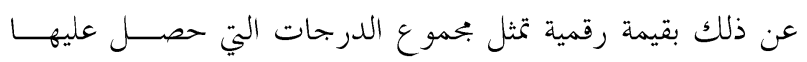

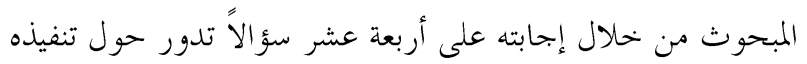

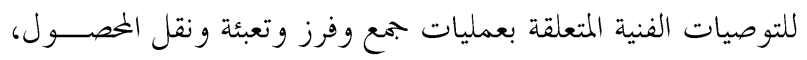
والتي سبق ذكرها في المستوى المعرفي للمبحوثين. وصف وقياس المتغيرات البحثية: يوضح الجدول رقم (1) درجات قياس المتغيرات البحثية التابعة والمستقلة.

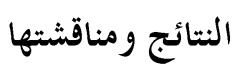

أولاً - المستوى المعوفي والتنفيذي للمزارعين المبحوثين فيما يتعلق بالتوصيات الفنية الخاصة بتقليل الفاقد من محصول الطماطم:

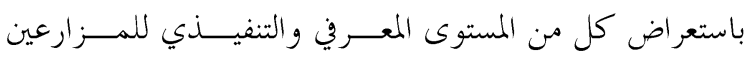
المبحوثين فيما يتعلق ببنود التوصيات الفنية الخاصة بتقليل الفاقد من

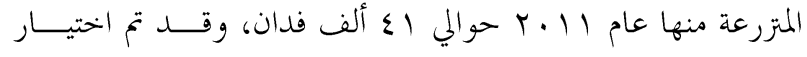

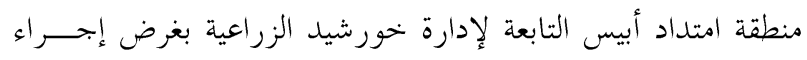

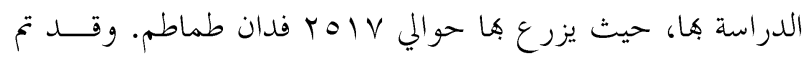

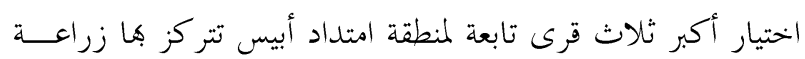

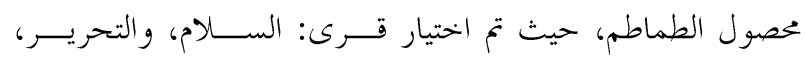
و الزهر اء. الشاملة والعينة: تمثلت شاملة هذا البحث في جميع مزارعي الطماطم

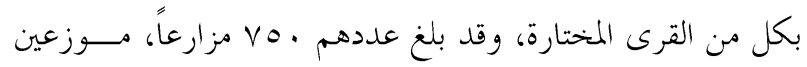

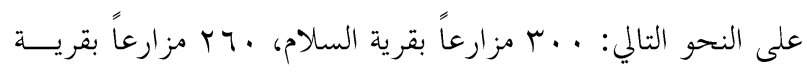

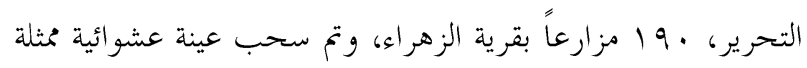

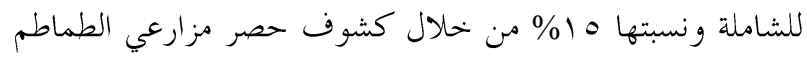

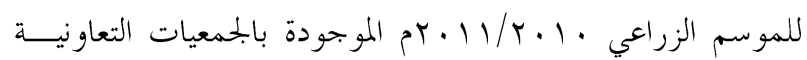

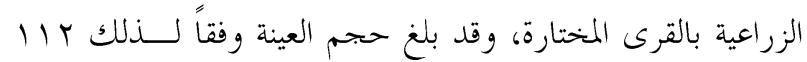

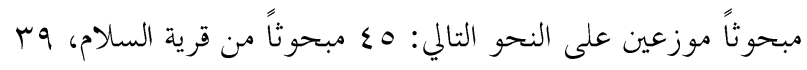

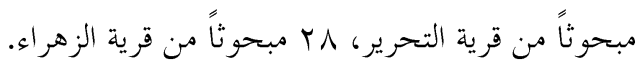
جمع البيانات: تم تجميع بيانات هذا البحث عن طريسـق الاســتبيان

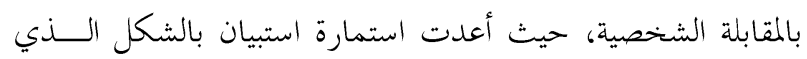

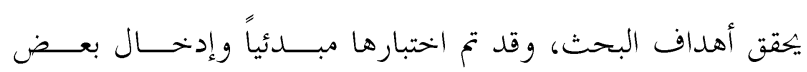

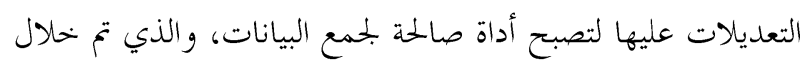

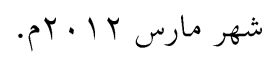
تحليل البيانات: تم عمل مصفوفة ارتباط لجميع المتغيرات لتحديــد

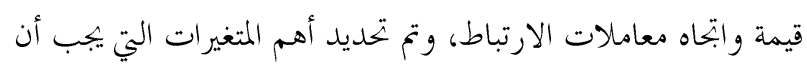
يتضمنها نموذج التحليل الكمي وهو الدالة اللوغاريتمية المزدوجة.

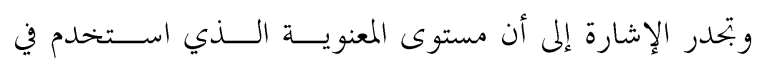

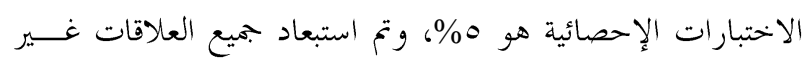

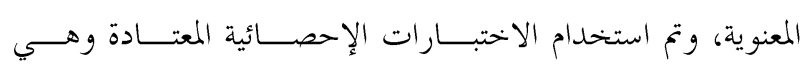
.F, T, R $\mathrm{R}^{-2}, \mathrm{R}$ التعاريف الإجر ائية للمصطلحات البحثية: الفاقد من الطماطم: يقصد به في هذا البحث كمية الثمار التي تتلف نتيجة لسوء معاملات تداول الخصول أثناء عمليات جمع وفرز وتعبئة ونقل الطماطم والتي لايستفيد بها جمهور المستهلكين. 
جدول ا ـ درجات قياس المتغيرات البحثية التابعة والمستقلة

\begin{tabular}{|c|c|c|}
\hline درجة القياس (قيمة رقمية) & 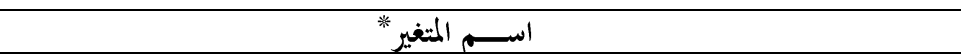 & 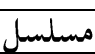 \\
\hline r صف & المستوى المعر في فيما يتعلق بالتوصيات الفنية الخاصة بتقليل الفاقد من محصول الطماطم & 1 \\
\hline 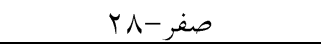 & المستوى التنفيذي فيما يتعلق بالتوصيات الفنية الخاصة بتقليل الفاقد من محصول الطماطم & r \\
\hline 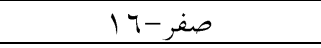 & 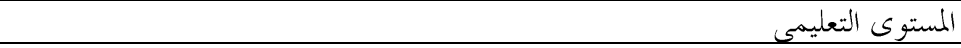 & r \\
\hline 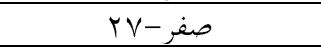 & الإلمام العام & $\varepsilon$ \\
\hline$Y I-V$ & الاتبحاه نهو المستحدثات الزراعية & 0 \\
\hline 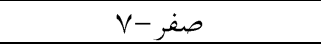 & التعرض لمصادر المعلومات الزراعية & 7 \\
\hline 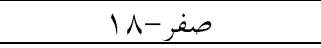 & المشار كة في الأنشطة الإرشادية & $\mathrm{V}$ \\
\hline 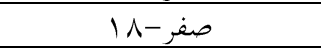 & التردد على مر اكز الخحدمات الزراعية & $\Lambda$ \\
\hline
\end{tabular}

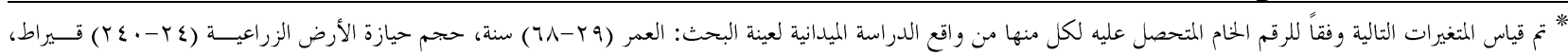

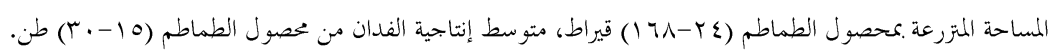

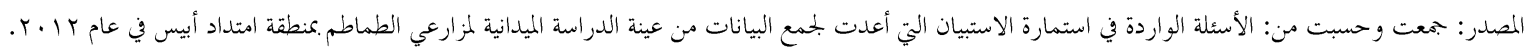

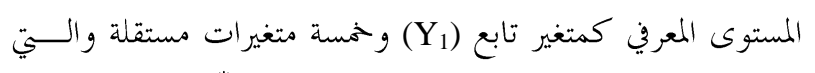
يوضحها نموذج الدالة اللوغاريتمية المزدوجة الآتية":

$\operatorname{Ln} Y=\operatorname{Ln} b_{0}+b_{1} \operatorname{Ln} X_{1}+b_{2} \operatorname{Ln} X_{2}+\ldots \ldots . .+b_{n} \operatorname{Ln} X_{n}$

$\operatorname{Ln} \mathrm{Y}_{1}=\operatorname{Ln} 6.978-0.725 \operatorname{Ln} \mathrm{X}_{1}+0.042 \operatorname{Ln} \mathrm{X}_{2}+0.087$ Ln $\mathrm{X}_{3}-0.006$ Ln $\mathrm{X}_{6}$

$-0.018 \operatorname{Ln} \mathrm{X}_{10}$

$(-0.346)$

$\mathrm{F}=120.313 \quad \mathrm{R}=0.922 \quad \mathrm{R}^{-2}=0.843$

حيث:

= المستوى المعرفي فيما يتعلق بالتوصيات الفنية الخاصة بتقليـلـل Y الفاقد من محصول الطماطم

$$
\text { العمر =X }
$$$$
\text { = X2 }
$$$$
\text { = الإلمام العام }
$$

= X6

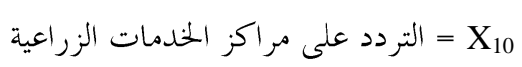

• بجدي الشوريجي، الاقتصاد القياسي (النظرية والتطبيق)، الطبعة الأولى، الدار المصرية

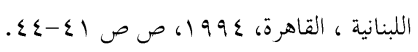

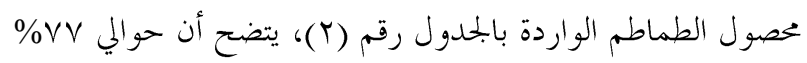

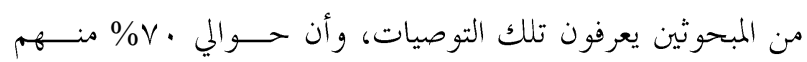

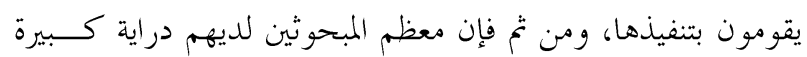

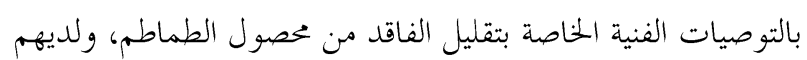

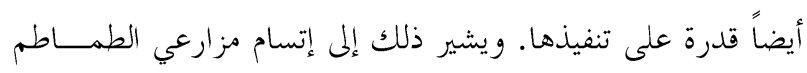

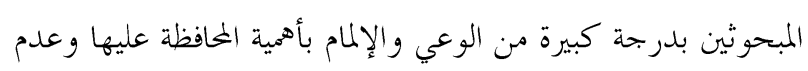

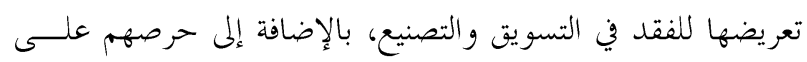
اكتساب الوسائل التي تمكنهم من ذلك.

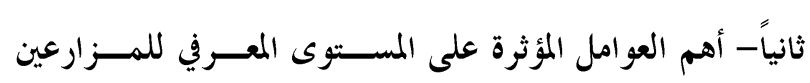

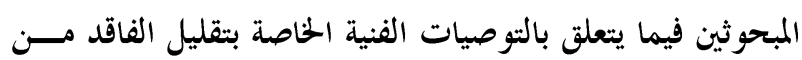

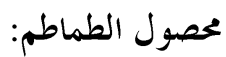
اتضح من تقدير مصفوفة الارتباط بين المتغيرات الممثلة، جدول

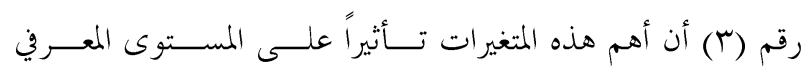

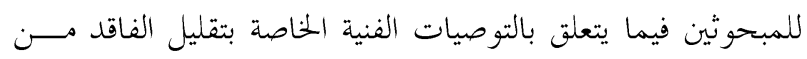

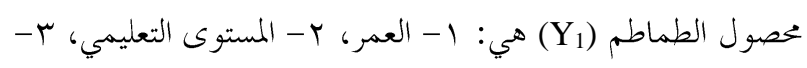

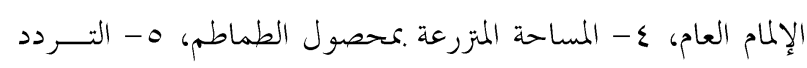

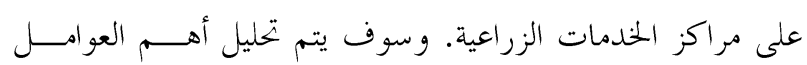
السابق ذكرها تحليلاً كمياً باستخدام الدالة اللوغاريتمية المزدوجة. و بناء" على ذلك فقد تم تكوين دالة لوغاريتمية مزدوجة للتعرف

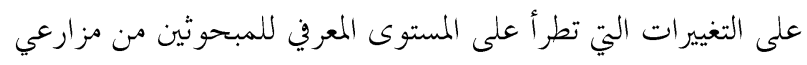

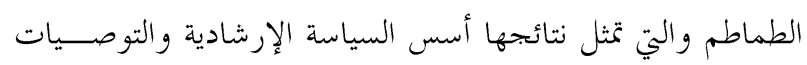

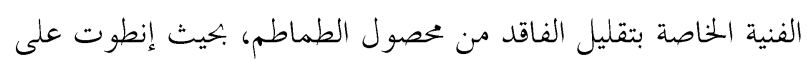


جدول r. توزيع المزارعين المبحوثين* وفقاً لكل من مستواهم المعرفي والتنفيذي لكل توصية على حده

\begin{tabular}{|c|c|c|c|c|c|}
\hline \multicolumn{2}{|c|}{ التنفيذ } & \multicolumn{2}{|c|}{ المعرفة هِا } & \multirow{2}{*}{ التوصيــة } & \multirow[b]{2}{*}{ 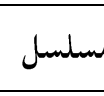 } \\
\hline لاينفذ & ينفذ & 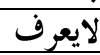 & 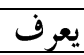 & & \\
\hline $9, \mathrm{~V}$ & $q \cdot, r$ & $9, \mathrm{~V}$ & $q \cdot, r$ & الوقت المناسب لجمع ثمار الطماطم & 1 \\
\hline 17,9 & $\Delta r, 1$ & $17 \pi, 9$ & $\Delta r, 1$ & الأسلوب السليم لقطف الثمار & r \\
\hline$\sum \uparrow, 1$ & or, q & $\mu, 1$ & 74,9 & العبوات المناسبة لجمع الثمار المقطوفة & $r$ \\
\hline $1 \%, 7$ & $\Lambda T, \varepsilon$ & 14,7 & $\Lambda T, \varepsilon$ & أهمية وضع الثمار البخموعة في مكان مظلل & $\varepsilon$ \\
\hline 10,7 & $\Lambda \varepsilon, \varepsilon$ & 10,7 & $\Lambda \varepsilon, \varepsilon$ & أهمية إزالة الأعناق من الثمار قبل تعبئتها & 0 \\
\hline$r \mathrm{r}, \varepsilon$ & $T \mathrm{~V}, \mathrm{~T}$ & $r \mathrm{r}, \mathrm{V}$ & $v v, r$ & أهمية التنظيف التام للثمار من أي أتربة عالقة فيا قبل تعبئتها & 7 \\
\hline$\varepsilon \varepsilon, \Lambda$ & $00, r$ & $\mu, \Lambda$ & $7 \Lambda, r$ & ضرورة استخدام الصناديق البلاستيك في تسويق ثمار الطماطم & $\mathrm{v}$ \\
\hline$r q,$. & $71,$. & $r T, \mathrm{~V}$ & $\mathrm{Vr}, \mathrm{r}$ & أهمية تدريج الثمار & $\Lambda$ \\
\hline$\varepsilon \cdot, r$ & 09,1 & $r V, q$ & $V T, 1$ & فو ائد توحيد درجة نضج الثمار بالعبوات & 9 \\
\hline$r_{0, v}$ & $T \varepsilon, r$ & $r \varepsilon, v$ & $v_{0, r}$ & المستوى المناسب لملىء العبو ات بالثمار & 1. \\
\hline $\mid \Lambda, r$ & $\Lambda 1, \Lambda$ & $1 \Lambda, r$ & $\Lambda 1, \Lambda$ & أضرار تبطين العبوات بالحشائش أو قش الأرز & 11 \\
\hline $\mathrm{r}_{\mathrm{T}, \mathrm{.}}$ & $v \varepsilon$, & $r \cdot, \Lambda$ & $V q, r$ & الوقت المناسب لنقل ثمار الطماطم إلى الأسو اق & ir \\
\hline$\varepsilon r, 0$ & 07,0 & $r ., 0$ & 79,0 & أهمية ترك مسافات بين العبوات عند رصها للتهوية & 14 \\
\hline$r v,$. & $7 \pi,$. & $r o, r$ & $V \varepsilon, v$ & أهمية تغطية العبوات المنقولة لحمايتها من التغيرات الجوية & $1 \varepsilon$ \\
\hline$r 9,9$ & $v \cdot, 1$ & $r r, v$ & $V V, r$ & المتوسط العام & \\
\hline
\end{tabular}

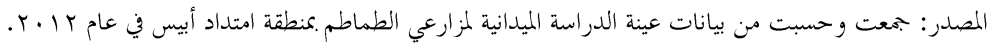

المعري بنسبة بع, ·. \%، ويوضح معامل المرونة الجزئية لمتغير "الإلمام

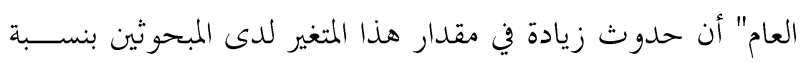

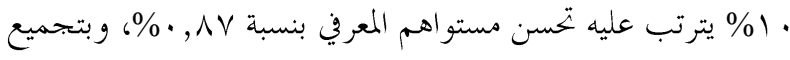

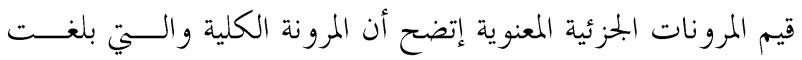

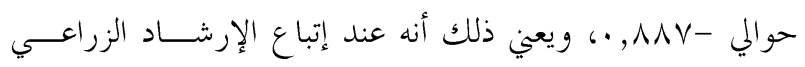

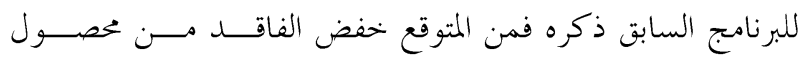

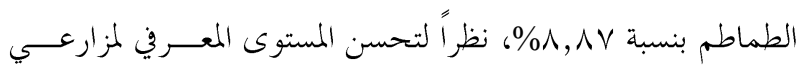
الطماطم فيما يتعلق بالتوصيات الفنية الخاصة بتقليل الفاقد منـــها، ومن ثم اقتناعهم بأهية وجدوى تلك التوصيات في هذا البحال .

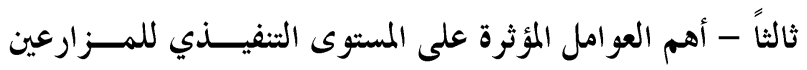

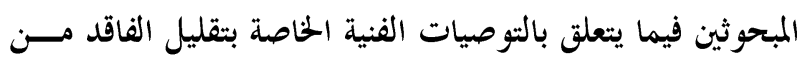

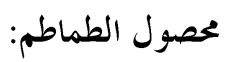

اتضح من تقدير مصفوفة الارتباط بين المتغيرات الممثلة، جدول

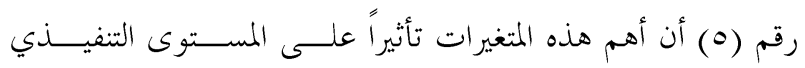

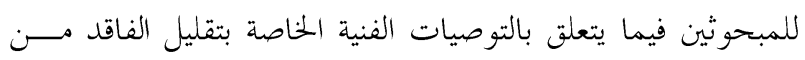

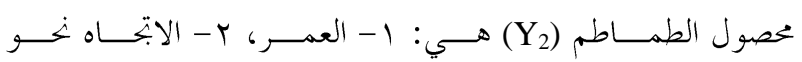

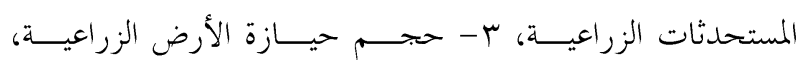

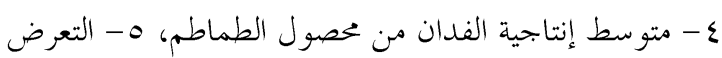

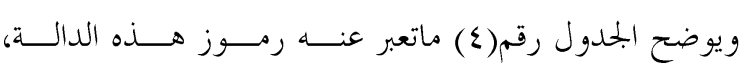

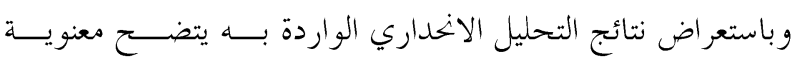

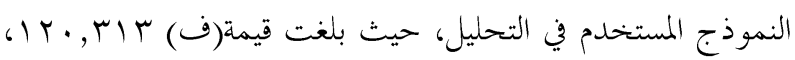

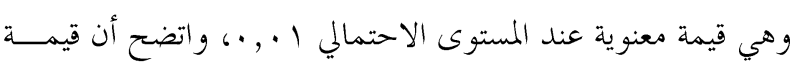

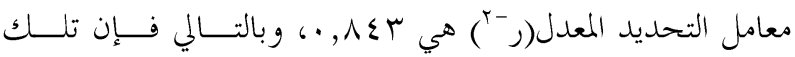

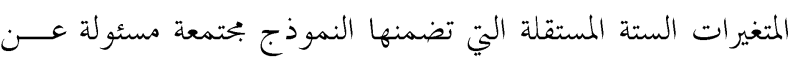

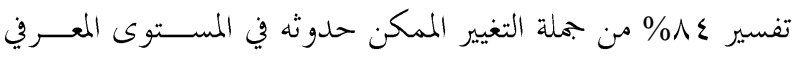

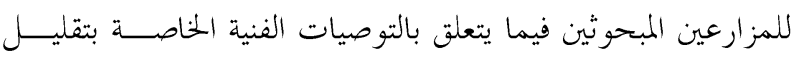

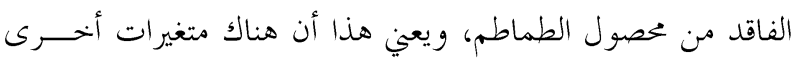

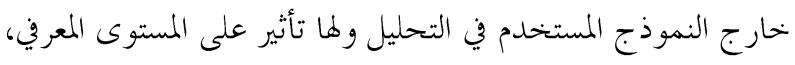

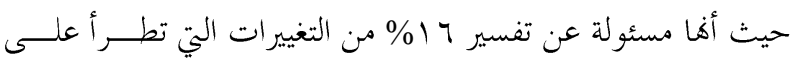

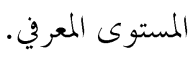

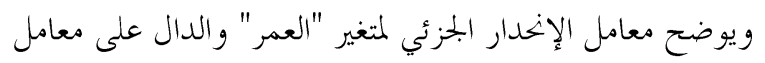

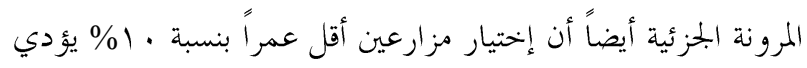

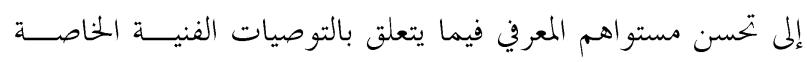

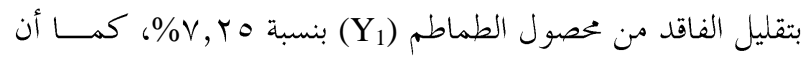

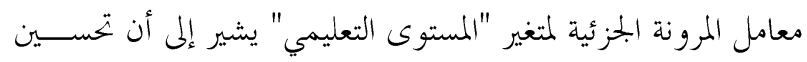

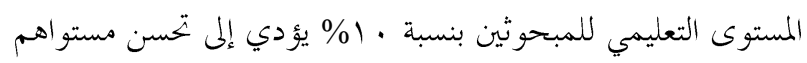


بحلة الإسكندرية للتبادل العلمى - (بحلدسب العددع) أكتوبر - ديسمبر r Y r T 
على المستوى الاحتمالي ا., •،حيث بلغت قيمة (ف) مالس, اس،

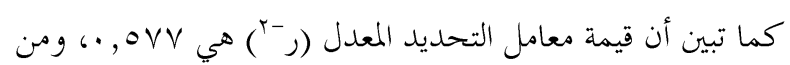

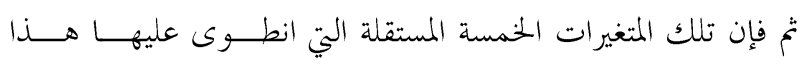

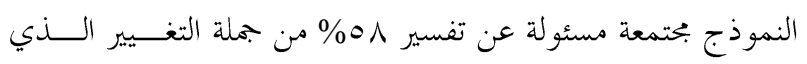

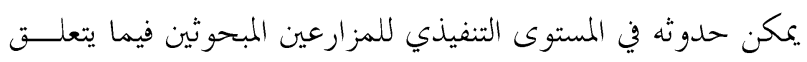
بالتوصيات الفنية الخاصة بتقليل الفاقد من محصول الطماطم، ويعني

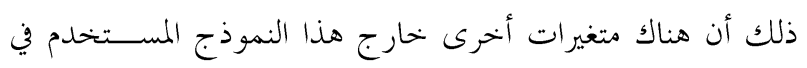
التحليل ذات تأثير على المستوى التنفيذي، وهي مسئولة عن تفسير التهري

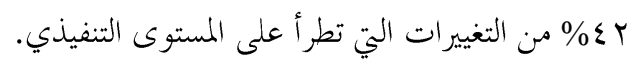
ويشير معامل المرونة الجزئية لمــتغير "العمـــــ" إلى أن اختيــار

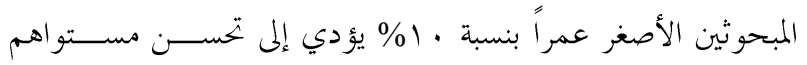

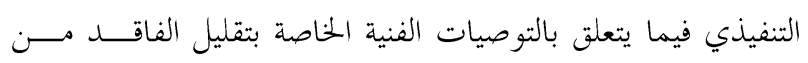

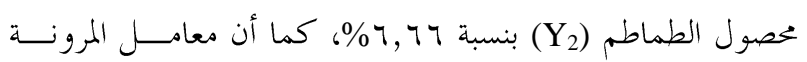

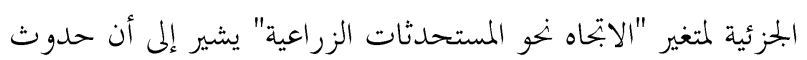

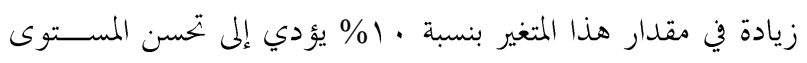

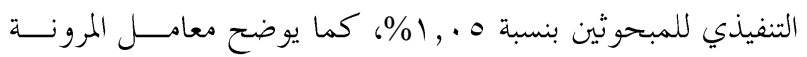

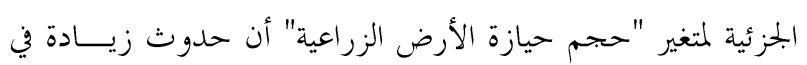

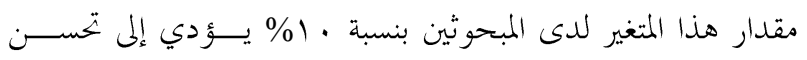

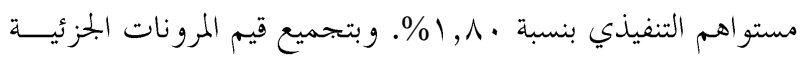

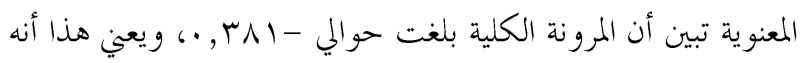

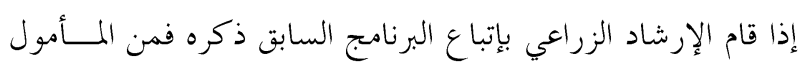

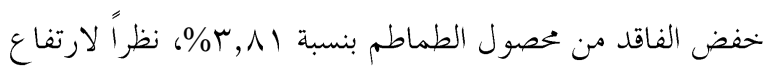

لمصادر المعلومات الزراعية. وسوف يتم تحليل أهم العو امل الســابق ذكرها تحليلاً كمياً باستخدام الدالة اللوغاريتمية المزدوجة.

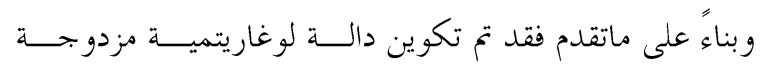
للتعرف على التغييرات التي تطرأ على المستوى التنفيذي للمزارعين ماني

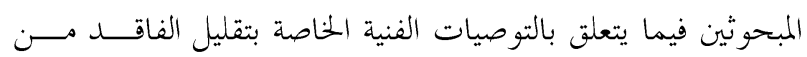

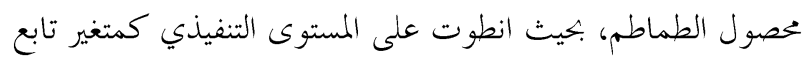

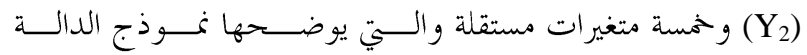
اللوغاريتمية المزدوجة الآتية:

Ln $\mathrm{Y}_{2}=\operatorname{Ln} 4.904-0.666 \operatorname{Ln} \mathrm{X}_{1}+0.105 \operatorname{Ln} \mathrm{X}_{4}+0.180$ $\operatorname{Ln} \mathrm{X}_{5}-0.005 \operatorname{Ln} \mathrm{X}_{7}$ $(-4.813)(2.376)$

$(3.000)$

$(-0.146)$

- $0.056 \operatorname{Ln} \mathrm{X}_{8}$ $(-0.407)$

$\mathrm{F}=31.318 \quad \mathrm{R}=0.772 \quad \mathrm{R}^{-2}=0.577$ حيث:

= المستوى التنفيذي فيما يتعلق بالتوصيات الفنية الخاصة بتقليل الفاقد من خصول الطماطم = $X_{1}$ = X4 = X5 = X7 X8

ويوضح الجلدول رقم (7) ماتعبر عنه رموز هذه الدالة، وقد تبين

عند تقدير العلاقة الانحدارية المتعددة لتلك الدالة أها معنوية كك ركـل

جدول ع. نتائج تحليل الانحدار المتعدد بين المتغيرات الخممسة المستقلة المختارة ومتغير المستوى المعرفي (Y1) للعينــة البحثيــة

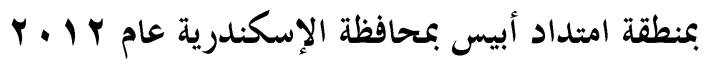

\begin{tabular}{|c|c|c|c|c|}
\hline مستوى المعنوية & "تيمة & $\begin{array}{c}\text { معامل الانحدار الجزئي } \\
\text { (ק) }\end{array}$ & 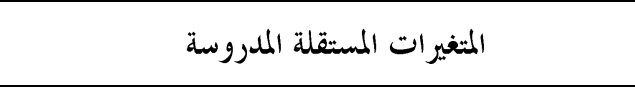 & $\hat{r}$ \\
\hline$\cdot, \cdot 1$ & $\Lambda, \cdot r r_{-}$ & $\cdot, \mathrm{V} Y \mathrm{O}-$ & 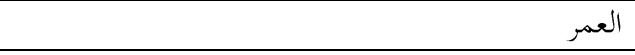 & 1 \\
\hline$\cdot, \cdot 1$ & $r, r \leqslant V$ & $\cdot, \cdot \sum r$ & المستوى التعليمى & $r$ \\
\hline., .0 & T,OVV & $\cdot, \cdot \Lambda \mathrm{V}$ & الإلمام العام & $r$ \\
\hline غير معنوي & $\cdot, \cdot \vee \wedge-$ & $\cdot, \cdots+-$ & المساحة المتزرعة بمحصول الطماطم & $\varepsilon$ \\
\hline 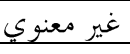 & $\cdot, \Gamma \varepsilon \neg-$ & $\cdot, \cdot 11-$ & التردد على مراكز الخدمات الزراعية & $\circ$ \\
\hline & & & \multicolumn{2}{|c|}{ 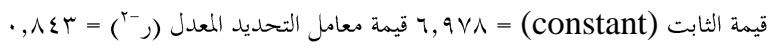 } \\
\hline & & & 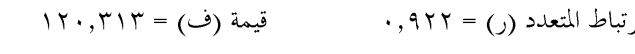 & قيمة مeاما \\
\hline
\end{tabular}


بحلة الإسكندرية للتبادل العلمى - (بحلدسب العددء) أكتوبر - ديسمبر r Y r T 
جدول 7. نتائج تحليل الانحدار المتعدد بين المتغيرات الخمسسة المستقلة المختارة ومتغير المستوى التنفيذي (Y2) للعينة البحثيــة

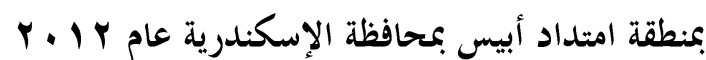

\begin{tabular}{|c|c|c|c|c|}
\hline مستوى المعنوية & ق ق قيمة "ت" & معامل الانحدار الجزئي (B) & المتغير ات المستقلة المدروسة & 5 \\
\hline$\cdot, \cdot, 1$ & $\varepsilon, \wedge \mid \mu_{-}$ & $\cdot, 777-$ & 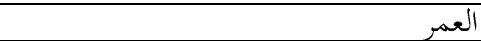 & 1 \\
\hline., .0 & $r, r \vee \tau$ & $\cdot, 1.0$ & الابتحاه نهو المستحدثات الزيراعية & $r$ \\
\hline$\cdot, \cdot, 1$ & $r, \ldots$ & $\cdot, 1 \wedge$. & حجم حيازة الأرض الزراعية & $\mu$ \\
\hline غير معنوي & $\cdot, 1 \leqslant 7-$ & $\cdot, \ldots 0-$ & متوسط إنتاجية الفدان من محصول الطماطم & $\varepsilon$ \\
\hline \multirow[t]{3}{*}{ غير معنوي } & $\cdot, \varepsilon \cdot \vee-$ & $\cdot, .07-$ & التعرض لمصادر المعلومات الزراعية & 0 \\
\hline & & قيمة معامل التحديد المعدل (ر-r) = OVV & $\varepsilon, q \cdot \varepsilon=($ constant $)$ & 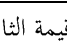 \\
\hline & & قيمة (ف) = & رتباط المتعدد (ر) = VVY, & ليمة معا \\
\hline
\end{tabular}

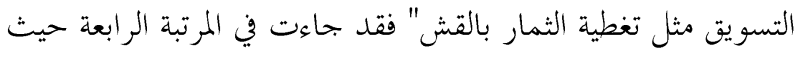

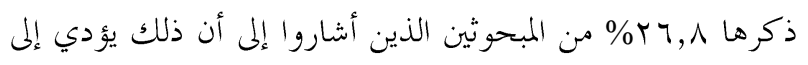

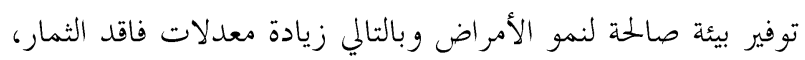

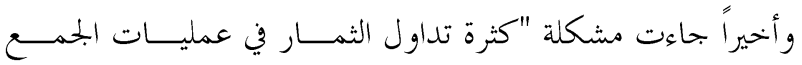

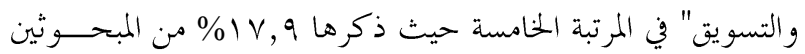
الذين أفادوا بأن إجراء تلك العمليات يتطلب عدداً كبيرًا من العمال المال

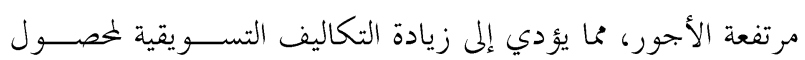

$$
\text { الطماطم. }
$$

خامساً - مقترحات المزارعين المبحوثين للتغلب على المشـــكلات التي تواجهرم عند تنفيذ بعض التوصيات الفنية الخاصة بتقليل

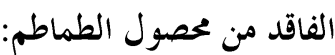

تمثلت المقترحات التي ذكرها المبحوثون للتغلب على المشكلات التي تو اجهرم عند تنفيذ بعض التوصيات الفنية الخاصة بتقليل الفاقد

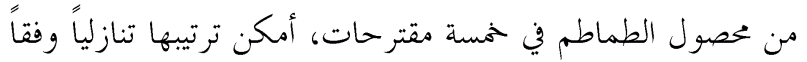
لتكرار ذكر المبحوثين لها في الجلدول رقم(^) على النحو التالي: قيام

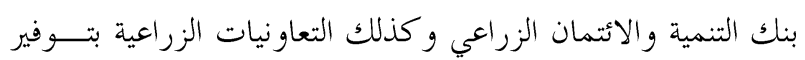

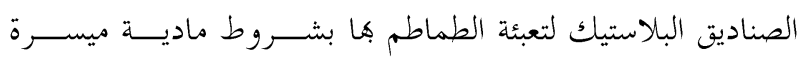

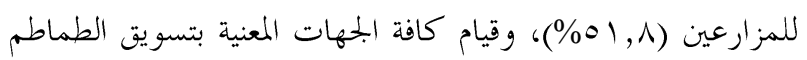

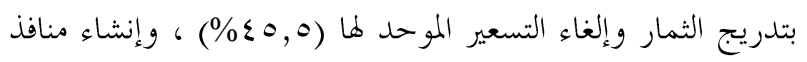
تسويقية لخصول الطماطم (·, ·ـع\%)، وتوفير معلومات تســـويقية

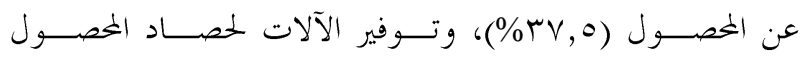

. $(\%$ Y,$\wedge)$
المستوى التنفيذي لمزارعي الطماطم فيما يتعلق بالتوصيات الفنيــة

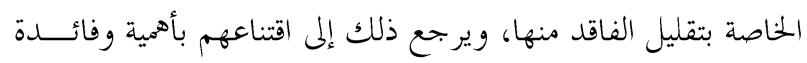
تلك التوصيات في هذا البمال.

رابعاً-أهم المشكلات التي تواجه المزارعين المبحوثين عند تنفيذهم

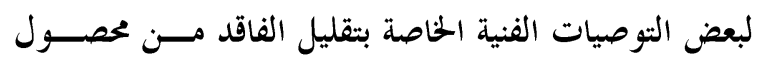

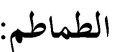

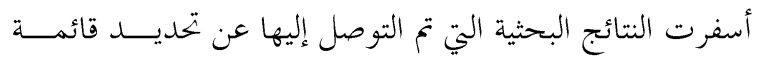

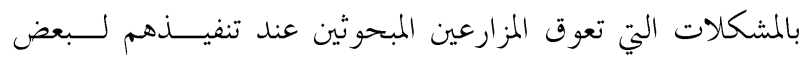

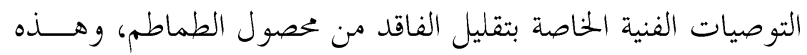

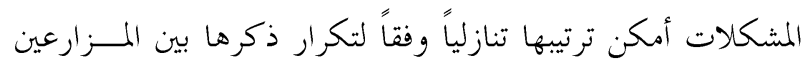
على النحو المبين في الجدول رقم (V)، و الذي يتضح منه أن مشكلة

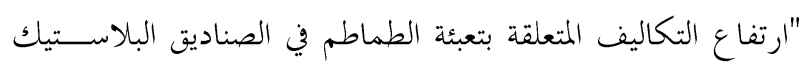

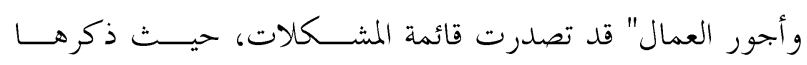

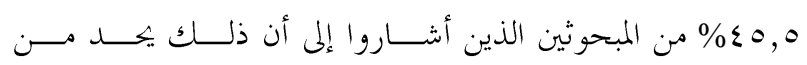

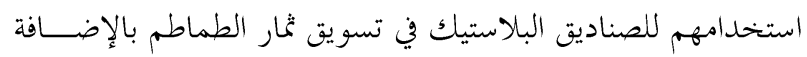

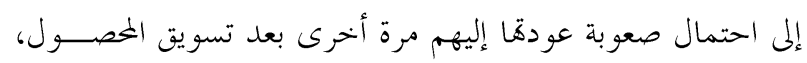
وجاءت مشكلة "عدم فرز وتدريج الثمار وتوحيد سعرها" في المرتبة

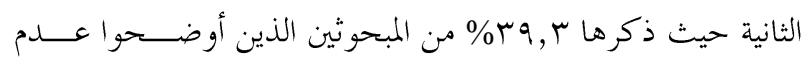

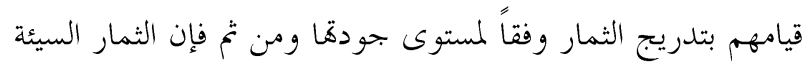

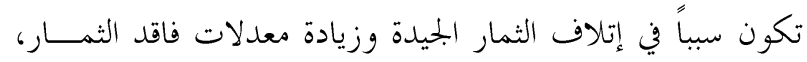

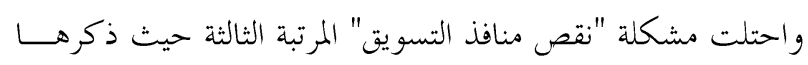

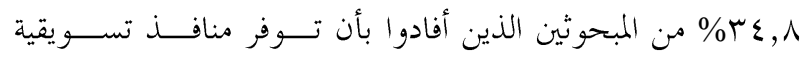

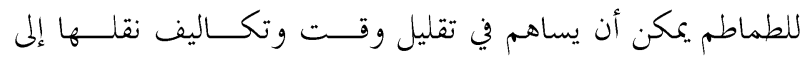

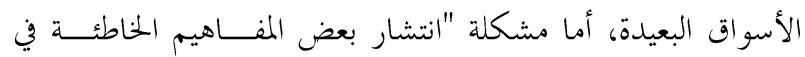


جدول V. أهم المشكلات التي تواجه المزارعين المبحوثين عند تنفيذهم لبعض التوصيات الفنية الخاصة بتقليــل الفاقــــ مــنـ محصول الطماطم

\begin{tabular}{|c|c|c|c|}
\hline$\%$ & نالتكرار & 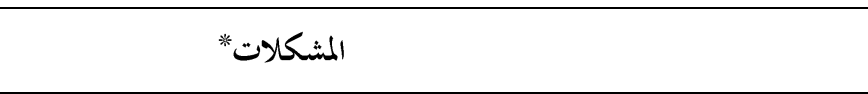 & b \\
\hline$\varepsilon 0,0$ & 01 & ارتفاع التكاليف المتعلقة بتعبئة الطماطم في الصناديق البلاستيك وأجور العمال & 1 \\
\hline$r q, r$ & $\varepsilon \varepsilon$ & عدم فرز وتدريج الثمار وتوحيد سعرها & $r$ \\
\hline$r \varepsilon, \Lambda$ & rq & نقص منافذ التسويق & $r$ \\
\hline$r T, \Lambda$ & $r$. & انتشار بعض المفاهيم الخاطئة في التسويق مثل تغطية الثمار بالقش & $\varepsilon$ \\
\hline 18,9 & $r$ r. & كثرة تداول الثمار في عمليات الجمع والتسويق & 0 \\
\hline
\end{tabular}

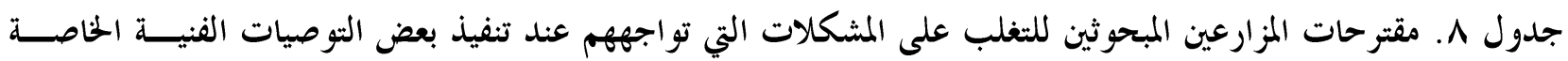

بتقليل الفاقد من محصول الطماطم

\begin{tabular}{|c|c|c|c|}
\hline$\%$ & ن ن التكرار & المقترحات* & b \\
\hline 01,1 & $0 \wedge$ & 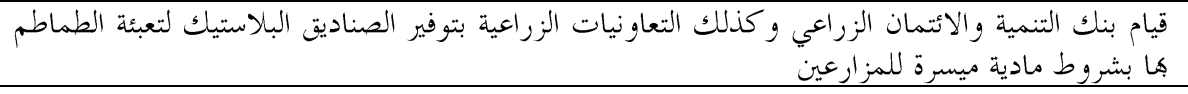 & 1 \\
\hline$\varepsilon 0,0$ & 01 & قيام كافة الجهات المعنية بتسويق الطماطم بتدريج الثمار وإلغاء التسعير الموحد لمال & $r$ \\
\hline$\varepsilon \cdot, \cdot$ & «o & إنشاء منافذ تسويقية لخصول الطماطم & r \\
\hline$r v, 0$ & $\sum r$ & توفير معلومات تسويقية عن المصصول & $\varepsilon$ \\
\hline$r т, \Lambda$ & $r$. & توفير الآلات لحصاد المحصول & $\circ$ \\
\hline
\end{tabular}

r- التركيز على زيادة ابتحاه هؤلاء الشباب من المزارعين نخو الأخذذ

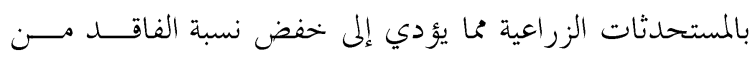
الطماطم.

ع -يستحسن عمل برنامج إرشادي يخصص للمز ارعين كبار الســن

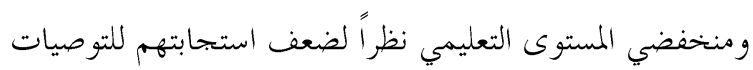

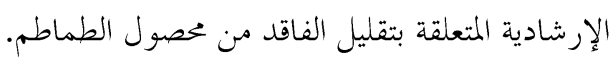

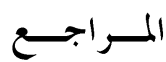

الجهاز المركزي للتعبئة العامة والإحصاء، الكتاب الإحصائي السنوي،

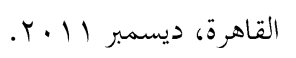

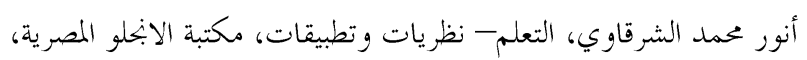

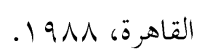

\section{التو صيات}

بناءً على النتائج البحثية التي توصلت إليها هذه الدراسة أمكــنـ

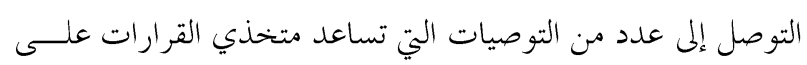
رسم السياسة الإرشادية الزراعية التي بمقتضاها يمكن تقليل

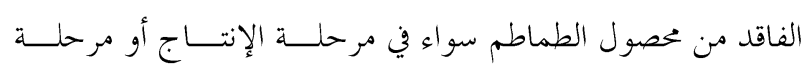

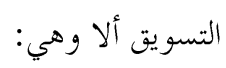
1 - ضرورة إكساب مزارعي الطماطم في مصر المعـــارف المتعلقـــة

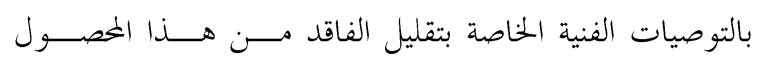

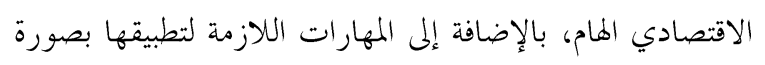
r-تستلزم السياسة الإرشادية التي يجب إتباعها لتقليل الفاقد مــن

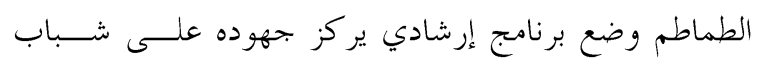

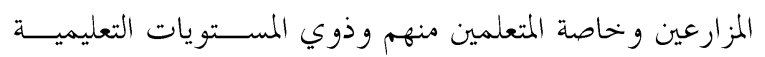
المرتفعة. 
محمد حامد زكي شاكر، رفض تبني بعض الممارسات المزرعية المستحدثة بين المزارعين المصريين، رسالة دكتوراه، كلية الزراعة، جامعة

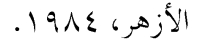

محمد عمر الطنوبي ومحمد السيد القاضي، العوامل المرتبطة بوعي وتطبيق الزراع للتوصيات الفنية لتقليل الفاقد من محصول الطماطم في قرية أبيار بمركز كفر الزيات - محافظة الغربية، بحلة الإسكندرية للبحوث

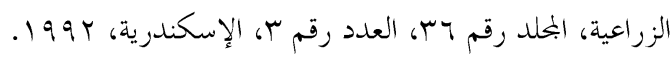
وزارة الزراعة واستصلاح الأراضي، قطاع الشئون الاقتصادية، الإدارة المركزية للاقتصاد الزراعي، نشرة الإحصاءات الزراعية، القاهرة،

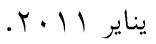

وزارة الزراعة واستصلاح الأراضي، قطاع الشئون الاقتصادية، الإدارة

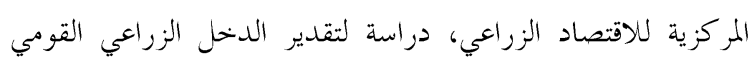

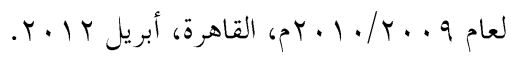

عادل عبد الحميد زقيزق،دور الإرشاد الزراعي في تقليل فاقد محصول الطماطم بقرية كوم البركة بمركز كفر الدوار- محافظة البحيرة، رسالة ماجستير، قسم الإرشاد الزراعي، كلية الزراعة، جامعة الإسكندرية، 1991.

عبد العزيز حسن الشبراوي ،دراسة مقارنة لأثر بعض الطرق الإرشادية

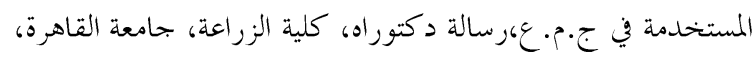
$.19 \vee \wedge$ عبد الفتاح الديدي، سوسيولوجية المعرفة، مقال منشور بجريدة الأهرام،

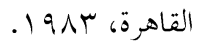
عواد محمد حسين وأحمد جمال الدين مدكور، الترشيد الاقتصادي للفاقد في ثمار الخضر و الفاكهة وأثره على الاقتصاد القومي المصري، بجلة

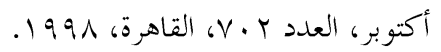
بحدي الشوربجي، الاقتصاد القياسي (النظرية والتطبيق)، الطبعــة الأولى، الدار المصرية اللبنانية ، القاهرة، ع99 19. 


\title{
ABSTRACT \\ Agricultural Extension Policy Suggestion for Decreasing the Loss of Tomato Production in Some Villages in the Abis Extent Region, Alexandria Governorate
}

\author{
Ahmad Mohamed Ali Ghozlan
}

This research aimed to determine the factors that affect on the response of tomato's farmers to the agricultural extension recommendations, that will decrease the loss of tomato, and through determining these factors can be suggestion Extension policy to achieve this purpose. This research was conducted in some villages of Abis Extent region, Alexandria governorate. Correlation matrix and multiple regression method through the double logarithmic function were used for data analysis.

The main results of this study revealed that:

- The percentage of respondents who know the technical recommendations on decreasing the loss of tomato crop was $77 \%$, while the respondents who implement it accounted for $70 \%$.

- A shortage of $10 \%$ in the level of age rat the same time rosining $10 \%$ for each of educational level and general literacy, it would decrease the loss of tomato crop by $8.87 \%$ due to improved knowledge level of the respondents in the technical recommendations associated with decreasing the loss of tomato crop.

- A shortage of $10 \%$ in the level of life, and at the same time make a raise of $10 \%$ of the level of each of the trend towards agricultural innovations and size acquisition of agricultural land, it would reduce the value of the loss of tomato crop by $3.81 \%$ due to improved operational level of the respondents in the technical recommendations on reducing wastage of the tomato crop.
- A shortage of $10 \%$ in the level of age, at the same time raising $10 \%$ for each of the attitude towards agricultural innovations and farm size, it would decrease the loss tomato crop by $3.81 \%$ due to improved operational level of the respondents in the technical recommendations associated with decreasing the loss of tomato crop.

- The study revealed that is some important problems that faced the respondents when carrying out some technical recommendations associated with decreasing the loss of tomato crop, they are follows :high costs associated with packing and wages of workers $(54.5 \%)$ non-sorting and grading of fruits, the lack of marketing outlets, diffusion of some misconceptions in marketing such as fruits straw coverage, and frequent trading fruits in combined operations and marketing $(17.9 \%)$.

- The respondents, suggestions to overcome these problems are: The Bank for Development and Agricultural Credit, as well as agricultural cooperatives by providing funds and plastics packaging tomatoes by the terms of material accessible to farmers, all concerned marketing tomatoes ranked fruits and cancel pricing consolidated it, create marketing outlets for tomato, providing marketing information for the crop, and provision of machinery to harvest the crop, where it was stated that the percentage ranged from $51.8 \%$ to $26.8 \%$ of the respondents in descending order 